\title{
The Effect of Concentration on Lubricating Properties of Aqueous Solutions of Sodium Lauryl Sulfate and Ethoxylated Sodium Lauryl Sulfate
}

\author{
Marian W. Sulek • Tomasz Wasilewski • \\ Krzysztof J. Kurzydłowski
}

Received: 16 October 2009/ Accepted: 12 July 2010/Published online: 25 July 2010

(C) The Author(s) 2010. This article is published with open access at Springerlink.com

\begin{abstract}
The objective of this study was to formulate new ecological lubricating substances, primarily water-based, and to verify their tribological and physicochemical properties. Initially, simple binary solutions were investigated. Then, various additives were added depending on application targets. Two alkyl sulfates were selected as additives modifying lubricating properties of water: sodium lauryl sulfate (SLS) and ethoxylated sodium lauryl sulfate (ESLS). They have an identical hydrophobic part in the form of an alkyl chain consisting of 12 carbon atoms. The $\mathrm{SO}_{4}{ }^{2-}$ anion forms the hydrophilic part in SLS molecules, whereas an ESLS molecule also contains two mers of ethylene oxide which cause an increase in its hydrophilicity relative to SLS. Both SLS and ESLS exhibit high surface activity measured by their surface tension. Micelles form in aqueous solutions of alkyl sulfates at low concentrations of the order of $1 \%$, whereas the presence of liquid crystalline phases can be found at the concentrations of 40 and $70 \%$. High surface activity and formation of structures in the solutions (micelles, mesophases) formed the basis for application of the compounds as additives modifying lubricating properties. Tribological properties of aqueous solutions of alkyl sulfates were verified with a four-ball machine (T02 tester) at a constant load of $2 \mathrm{kN}$. The values of friction coefficient $(\mu)$ were a measure of motion resistance, while the wear scar diameter $(d)$ was a measure of wear. Alkyl sulfates significantly improve tribological properties of water. The
\end{abstract}

M. W. Sulek · T. Wasilewski ( $\square)$

Department of Chemistry, Technical University of Radom,

Chrobrego 27, 26-600 Radom, Poland

e-mail: tomasz.wasilewski@pr.radom.pl

K. J. Kurzydłowski

Materials Design Division, Technical University of Warsaw,

Woloska 131, 02-507 Warszawa, Poland coefficient of friction decreased sixfold and the wear scar diameter decreased by as much as twofold relative to the base. Non-monotonic changes in the tribological properties measured were observed as a function of concentration of additives. An attempt was made to relate those atypical changes with the presence of micelles and mesophases in both the surface phase and the bulk phase. In the model proposed the whole concentration range was divided into four areas in which tribological properties correspond well with physicochemical properties, particularly with the structures formed in solutions and at the interface.

Keywords Antiwear additives - Friction modifiers . Boundary lubrication chemistry - Wear mechanisms . Lyotropic liquid crystals · Water-based lubricants

\section{Introduction}

Water is often used as a base for ecological, fire-resistant operational fluids. It has a number of disadvantages such as corrosive action, insufficient lubricating properties, a narrow range of working temperatures and low viscosity. However, it also has advantages: it is inexpensive and easily available, and it does not have a harmful effect on living organisms-it poses practically no hazard to the natural environment. Additives modifying lubricating properties of water have been suggested in literature [1-15]. The number of those publications is relatively not very large and their authors do not refer to the current state of the art in the field of surfactants and their solutions. This rationalizes systematic investigations of aqueous solutions of surfactants in the context of applications as operational fluids. Modern operational fluids are ultimately expected to be multicomponent aqueous solutions of surface-active substances (surfactants). 
The results of the research on antiseizure properties of aqueous solutions of alkyl sulfates have been presented in [7]. Even simple binary systems have surprisingly high values of scuffing load $\left(P_{t}\right)$, seizure load $\left(P_{\mathrm{oz}}\right)$, and limiting pressure of seizure $\left(p_{\mathrm{oz}}\right) ; P_{\mathrm{oz}}$ reach maximum values characterizing a four-ball machine (T-02 tribotester). Changes in the values being measured $\left(P_{t}, P_{\mathrm{oz}}, p_{\mathrm{oz}}\right)$ as a function of concentration were not monotonic. So, the question was if the character of the changes observed was exclusively a feature characterizing the quantities describing seizure or if it includes also other friction conditions. Therefore, tribological studies were carried out at a constant load $(2 \mathrm{kN})$ using a four-ball tester (T-02 tribotester).

The tribological studies were preceded by an analysis of physicochemical studies whose aim was to connect resistance to motion and wear with surface activity and the structures being formed in aqueous solutions of the compounds examined and at the solid-solution interface.

\section{Experimental Procedures}

\subsection{Materials}

Sodium lauryl sulfate (SLS) and ethoxylated sodium lauryl sulfate (ESLS) were used in the investigation (Fig. 1). The molecule contains a sulfate group $\left(\mathrm{SO}_{4}{ }^{2-}\right)$ exhibiting affinity for polar solvents. A $\mathrm{C}_{12}$ alkyl chain shows affinity for non-polar solvents. The sulfur atom is attached to carbon via the oxygen atom (the $-\mathrm{C}-\mathrm{O}-\mathrm{S}-$ bond). The sulfate group of SLS is attached directly to the alkyl chain. In the case of the ethoxylated form there is a fragment of a poly(ethylene oxide) chain between the sulfate group and the alkyl chain.

Aqueous solutions of individual compounds in the concentration range of 0.001 to $40 \mathrm{wt} \%$, and additionally 55 and $70 \mathrm{wt} \%$ for ESLS, were used as lubricating substances. The tests were carried out for pure water as a base. The solutions were prepared using the gravimetric method.

A commercial product (trade name: Rokanol LP) containing $90 \%$ of SLS supplied by PCC Rokita (Poland) was used in the tests. The other product used was Texapon N70 produced by Cognis-Henkel (Germany). It contained 70\% of SLS ethoxylated with $2 \mathrm{~mol}$ of ethylene oxide (ESLS). Redistilled water was used to prepare the solutions in all the cases.

Frictional tests were conducted using a steel-steel friction couple. Friction pair elements were made of $100 \mathrm{Cr} 6$ bearing steel, with surface roughness $R_{\mathrm{a}}=0.032 \mu \mathrm{m}$ and hardness $60 \div 65$ HRC.

\subsection{Research Methods and Equipment}

\subsubsection{Surface Tension}

Surface tension measurements were carried out at $20{ }^{\circ} \mathrm{C}$ by means of a Lauda TD1 tensiometer. The results presented are the arithmetic mean from five independent measurements.

\subsubsection{Viscosity}

The Brookfield LVDV-III Ultra rheometer was used to measure viscosity. The rotational speed of the spindle was $10 \mathrm{rpm}$ and the measurement temperature was $20^{\circ} \mathrm{C}$.

\subsubsection{Identification of Liquid Crystalline Structures}

Microscopy under polarized light and X-ray diffraction were used to identify liquid crystalline structures. A Polar polarizing microscope produced by PZO-Warszawa (Poland) with a digital camera (magnification $300 \times$, measurement temperature $20^{\circ} \mathrm{C}$ ) and a diffractometer $\mathrm{D}$ 5005, Bruker/AXS (radiation $\mathrm{Cu} \mathrm{K} \alpha(\lambda=1,542 \AA)$, a graphite monochromator, temperature $20^{\circ} \mathrm{C}$, measurement time $10 \mathrm{~min}$, measurement range from $1^{\circ}$ to $10^{\circ}$ ).

\subsubsection{Tribological Properties}

A four-ball machine, T-02 tribological tester, produced by IteE Radom (Poland) was used. The steel balls used in the tests had a diameter of $1 / 2$ in. The tests at a steady load during measurement were performed at a rotational speed of the spindle of $200 \mathrm{rpm}$. Test duration was $900 \mathrm{~s}$ and
Fig. 1 Formulas of sodium lauryl sulfate (SLS) and ethoxylated sodium lauryl sulfate (ESLS)
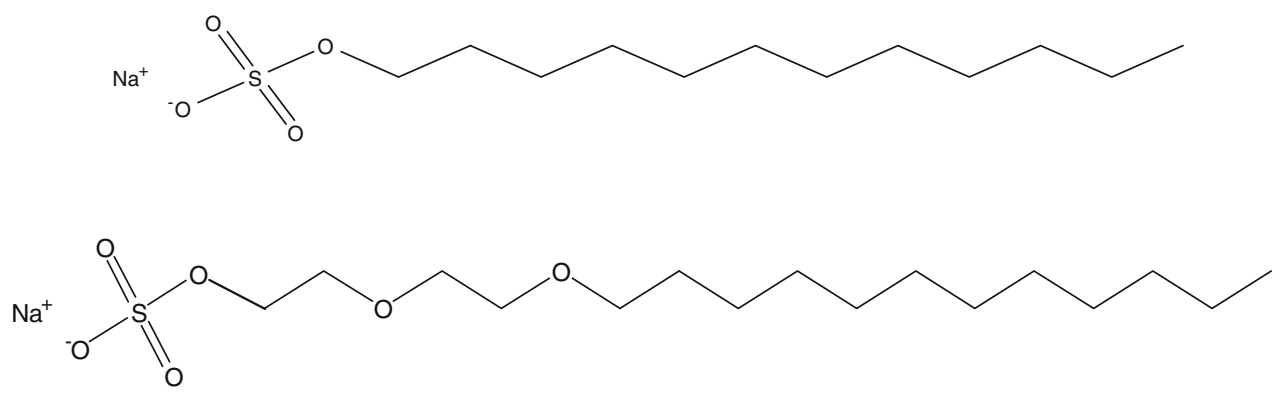
friction pair load was $2.0 \mathrm{kN}$. The coefficient of friction $(\mu)$ was determined by measuring friction torque $\left(M_{\mathrm{T}}\right)$. The following formula was applied:

$\mu=222.47 \frac{M_{\mathrm{T}}}{P}$

where $M_{\mathrm{T}}$ is the friction torque ( $\left.\mathrm{N} \mathrm{m}\right), P$ is the applied load $(\mathrm{N})$, the coefficient 222.47 results from the distribution of forces in the four-ball machine [16].

Changes in the coefficient of friction $(\mu)$ as a function of time were analyzed for each lubricating substance. The value of $\mu$ was recorded every $1 \mathrm{~s}$ during the test. On the examplary dependences of the coefficient of friction on time, the individual points are averaged values from $30 \mathrm{~s}$ time intervals.

Then after each measurement the averaged value of the coefficient of friction from the whole $900 \mathrm{~s}$ test was calculated. The values presented in the dependences of $\mu$ on additive concentration constitute an average of three independent frictional tests.

The temperature of the lubricating substance was measured by means of a thermocouple immersed into lubricating substance during friction.

Measurements of wear scar diameters $(d)$ were conducted parallel and perpendicular to the direction of friction after each test. Then an arithmetic mean was calculated for the values obtained. A Polar reflection microscope produced by PZO-Warszawa (Poland) was used to measure the diameters.

\section{Results and Discussion}

Adsorption of lubricant additives on solid surfaces significantly affects the tribological values measured. Although the quantities characterizing adsorption are determined under static conditions, they may be referred to dynamic friction conditions in the first approximation. Amphiphilic surface-active agents in which it is possible to distinguish a hydrophilic part and a hydrophobic part are a particularly interesting research subject. They exhibit high surface activity. They can form micelles and liquid crystalline structures both at the interface and in the bulk phase [17-30]. The ample experimental material makes it possible to predict the effect of the structure of a compound and the share of the hydrophilic and hydrophobic parts on adsorption properties [27, 28, 31-33]. An increase in the hydrophobic part generally brings about a considerable increase in the excess values and a decrease in the critical concentration of surface and bulk micelles [17-30]. According to Traube's rule, an alkyl chain growth by a $\mathrm{CH}_{2}$ group causes a threefold reduction in CMC and CSAC [24], but a growth of the hydrophilic part results in a decrease in the amount of the adsorbed compound and a shift in the values of CMC and
CSAC towards higher concentrations. The dependences can be connected with an increase in solubility together with a growth of the hydrophilic part [27, 28].

Adsorption of surfactants on interfacial surfaces and formation of surface structures have been a subject of a number of studies employing various measurement techniques. The most important ones include: surface tension measurements, ellipsometry, atomic force microscopy (AFM), X-ray and neutron scattering, NMR spectroscopy, and colorimetric methods [34-43]. The method used to determine adsorbability of two alkyl sulfates from their aqueous solutions was the measurement of surface tension whose measure was a force needed to detach a ring-shaped platinum wire from the surface of a liquid.

Surface tension $(\sigma)$ is a measure of surface activity of compounds and characterizes adsorption at the interface. A reduction in the $\sigma$ value as a function of concentration of a solution component indicates positive adsorption whereas an increase in the $\sigma$ value indicates desorption. Surface tension is a feature of the system. It depends on such factors as the solvent, the surface, and the structure of adsorber molecules. The dependence of surface tension on concentration for surfactants can be approximated by two straight lines. The point of their intersection may be used to determine CMC.

\subsection{Micellar Solutions of Alkyl Sulfates}

According to our own investigation results and literature data, SLS and SLS ethoxylated with 2 mol of ethylene oxide (ESLS) form micellar solutions in water. The values of the critical micelle concentration (CMC) are about $0.24 \mathrm{wt} \%$ (SLS) and $0.11 \mathrm{wt} \%$ (ESLS) [7, 44-50]. These results are unexpected as the hydrophilic part in the ESLS molecule is expanded by addition of two molecules of ethylene oxide which should increase water solubility and "shift" the CMC value towards higher concentrations. In order to confirm literature data, measurements of surface tension $(\sigma)$ were conducted for the solutions. Its changes as a function of concentration have been presented in Fig. 2.

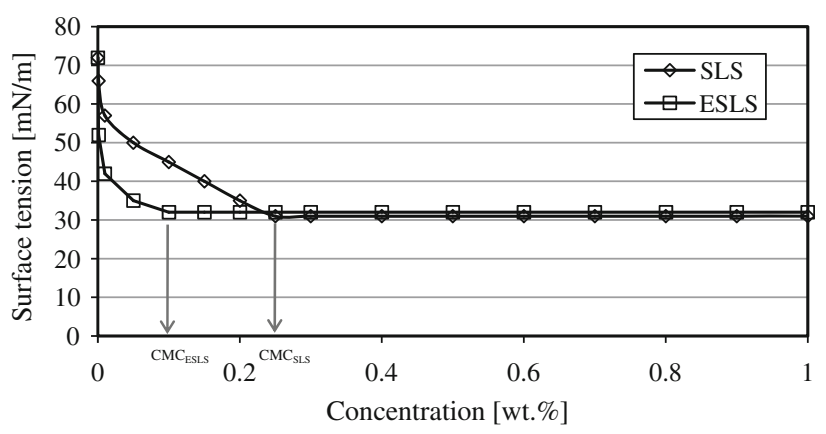

Fig. 2 Dependence of surface tension on concentration of aqueous solutions of SLS and ESLS 
The $\sigma$ values for SLS and ESLS can be estimated as about 0.25 and $0.1 \%$, respectively.

The results obtained confirm the gradation of changes in the CMC values. The values of surface tension for ESLS solutions are approximately constant from the concentration of about $0.1 \%$, whereas the surface tension values for SLS solutions are constant from the concentration of more than two times higher. In the concentration range of 0 to over $0.2 \%$, the $\sigma$ values are higher for SLS solutions and the differences in the $\sigma$ values between the two compounds decrease with an increase in concentration.

The unexpected differences in the $\sigma$ and CMC values, compared to the properties of hydrophilic-hydrophobic molecules of both compounds, may be explained by the formation mechanism of surface micelles. They form at the solid-solution interface from a concentration value called the critical surface aggregation concentration (CSAC). The process of surface micelle formation proceeds according to the mechanism of micelle formation in the bulk phase after taking into account the interaction with the surface. The hydrophobic effect thus predominates [31-33]. Surface micelles may differ from micelles in the bulk phase in the shape and configuration (position in relation to the surface). They are also more ordered than micelles in the bulk phase $[23,26,51,52]$. Formation of surface micelles does not result from adsorption of micelles in the bulk phase and takes place at lower concentrations (CSAC < CMC) [22, 23]. The process of surface micelle formation begins at the CSAC concentrations and ends after reaching the $\mathrm{CMC}$ value. There are no thermodynamic stimuli above the CMC value which would stimulate further adsorption and the chemical potential does not change. The surface phase is fully set and formation of micelles in the bulk phase begins [25, 26, 53-55].

Alkyl sulfates used in this investigation have an identical hydrophobic part in the form of an alkyl chain containing 12 carbon atoms. They differ, however, in the hydrophilic part. An SLS molecule has a sulfate anion, and ESLS has additionally two molecules of ethylene oxide. The interactions of the anion with the solvent and the surface are electrical in nature while oxygen from the ether group interacts via hydrogen bonds.

It follows from the analysis of the CMC and surface tension values for the alkyl sulfate solutions that the process of surface micelle formation proceeds in ESLS solutions at lower concentrations than in SLS solutions. It should be noted in this context that two factors affect the composition and structure of the surface phase: (a) the enthalpy connected to interactions of the surfactant with the surface and the solvent and (b) the entropy connected to the spatial arrangement of individual functional groups [28].

The lack of correlation between the structure of both the compounds and the measured CMC and surface tension values can be interpreted on the basis of a two-stage mechanism of adsorption. In the first stage, monomers and micelles diffuse to the interface and the compound with higher hydrophobicity appears in higher concentration in the "near-interfacial" space. The SLS molecule has a higher share of the hydrophobic part compared to ESLS and its concentration in that space should be higher. In the second stage, adsorption of monomers from the bulk phase and monomers formed due to decomposition of micelles takes place [17-30, 56]. This process becomes complicated because solvated surfactant molecules adsorb on the surface [17-30, 57]. Both SLS and ESLS are solvated due to electrostatic interactions of the type: surfactant charge (anion)water dipoles. In addition, ESLS molecules undergo hydration as a result of formation of hydrogen bonds of water molecules with two oxygen atoms from ether groups. Interactions of the hydrophilic part of the ESLS molecule with the surface are thus weaker (enthalpic separation) than interactions of the hydrophilic part of the SLS molecule and it is "pushed out" of the surface towards the solvent [17-30, 58]. Hence, it is the entropic effect connected with spatial positioning of the hydrophilic part that decides about adsorption up to the concentration value equal to CMC. Consequently, the surface covered by a single ESLS molecule is smaller than SLS and the number of adsorbed molecules is larger and the degree of packing of the surface phase is higher.

After reaching CMC which is different for the two alkyl sulfates, the process of formation of surface micelles is terminated and surface tensions of the SLS (CMC $\approx$ $0.2 \%)$ and ESLS (CMC $\approx 0.1 \%$ ) solutions are comparable. The unexpected, from the viewpoint of the structure of the two compounds, gradation of the changes in the $\sigma$ values can be interpreted as a result of a positive effect of solvation via hydrogen bonding of the ESLS molecule on adsorbability of this compound. The proposed adsorption mechanism is hypothetical but it offers a good interpretation of experimental studies and corresponds with the current theories of adsorption of surfactants at the solid-solution interface [17-30]. The credibility of this hypothesis does not interfere with interpretation of the results of tribological tests. It has been established that formation of the surface phase is over at concentrations of the order of tenths of one percent.

\subsection{Lyotropic Liquid Crystals}

Micelles are components of the structure of lyotropic liquid crystals (LLCs). Their ordering results from long-range interactions. Various mesophases may form depending on the type of micelles, solubility, concentration and temperature. The most important phases are: nematic, lamellar, hexagonal, and regular.

In order to confirm the presence of mesophases in alkyl sulfate solutions, microscopic examination under polarized light and low-angle X-ray spectroscopy examination were 
carried out. Figure 3 shows the textures of liquid crystalline structures and X-ray patterns which unequivocally point to the formation of the following mesophases:

- lamellar for $40 \%$ aqueous solutions of SLS,

- hexagonal and lamellar for 40 and $70 \%$ solutions of ESLS, respectively.

The hexagonal phase may appear in a wide range of concentrations (30-60\%) and in a wide range of temperatures [44]. It exhibits a particularly high viscosity which makes it easily distinguishable. The viscosity may be so high that the liquid does not flow. The hexagonal phase is made up of cylindrical micelles. Lamellar phases also occur in a wide range of concentrations, just like hexagonal phases, but at higher concentrations [44]. The characteristic feature is a reduction in viscosity in comparison with the hexagonal phase and that is also an indirect proof of their presence.
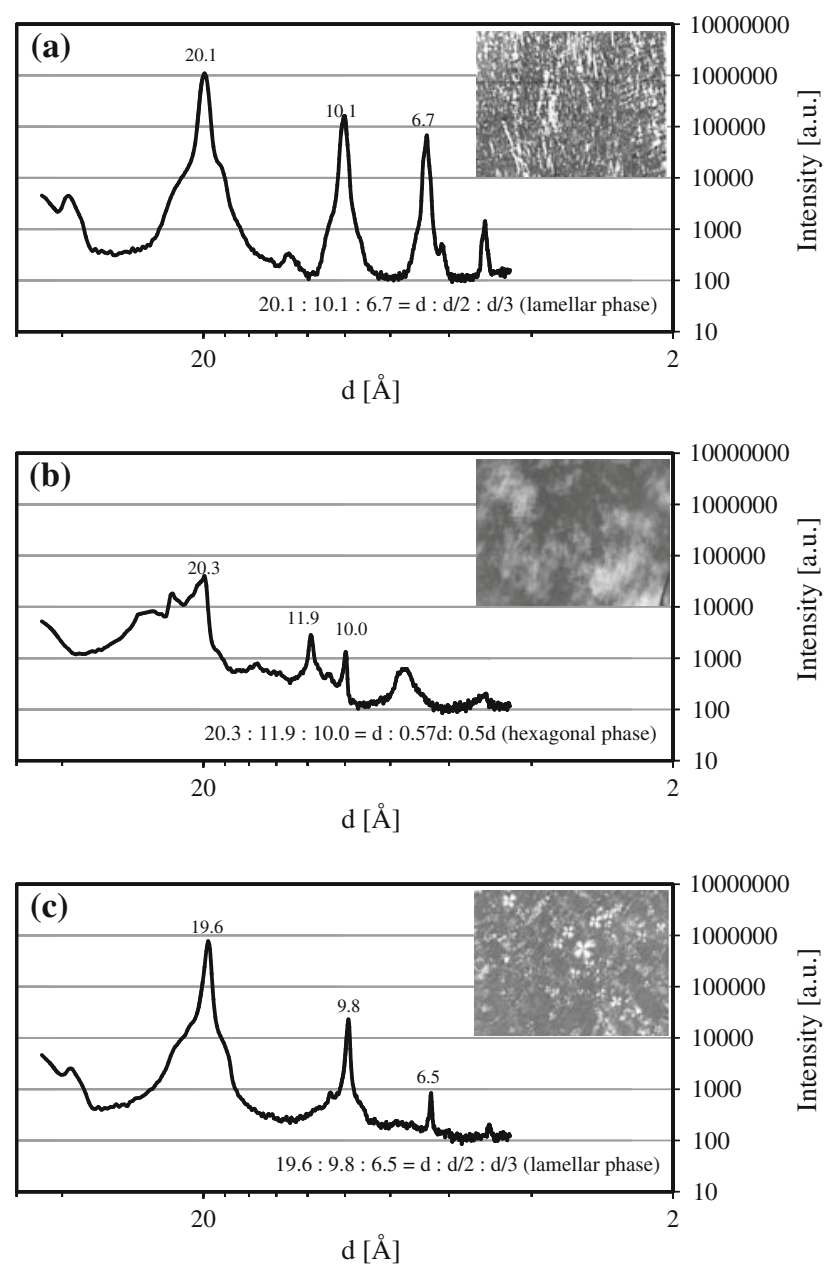

Fig. 3 X-ray patterns and microscope images under polarized light obtained for: a $40 \%$ aqueous solution of SLS, b $40 \%$ aqueous solution of ESLS, and $\mathbf{c} 70 \%$ aqueous solution of ESLS
The presence of mesophases in alkyl sulfate solutions could also be confirmed by analyzing changes in the coefficient of viscosity $(\eta)$ as a function of concentration of the compounds [7]. The ESLS solutions reach the $\eta$ value of $10^{7} \mathrm{mPa} \mathrm{s}$ at the concentration of $40 \%$, which signifies the presence of the hexagonal phase. An increase in concentration causes a drop in viscosity to the value of $10^{5} \mathrm{mPa} \mathrm{s}(70 \%)$ and a change of the hexagonal phase into the lamellar one. The presence of the hexagonal phase in $40 \%$ solutions of SLS can be confirmed as the solutions exhibit high values of $\eta$ of the order of $10^{8} \mathrm{mPa}$.

Alkyl sulfates exhibit high surface activity and the adsorption equilibrium constant has relatively high values. As a result, the concentration in the surface phase may be many times higher than in the bulk phase. The concentration in the surface phase may reach the values which enable the formation of liquid crystalline phases at concentrations around one percent in the bulk phase.

\subsection{Motion Resistance and Wear Under Steady Load}

The type of lubricating substances used depends primarily on application trends but also on the kind of material, geometry, and friction node operating conditions. Lubricating substances are multicomponent solutions in which individual components perform specific functions. From the point of view of tribological properties, an important role is played by the contact zone of a lubricating substance with the material of friction pairs. In accordance with a principle generally accepted in physical chemistry, a solution can be divided into a bulk phase and a surface phase. The latter determines lubrication. Due to external forcings (load, relative motion), the surface phase, formed under static conditions, turns into a lubricant film. Therefore, when selecting additives, particular attention should be paid to their adsorbability at the solid-solution interface. Other determinants affecting the quality of lubricating substances, such as viscosity, heat conduction, and safety at the stages of production, application, and utilization, should obviously also be taken into account.

The results of studies on surfactants as lubricity modifiers for both oil and water bases have been presented in literature [1-15]. The interpretation of the results obtained is often based on simplified physicochemical models. The extensive theoretical and experimental research work on surfactant solutions has been used to a limited extent.

Studies on various kinds of surfactants (non-ionic, anionic, cationic and amphoteric) as additives modifying lubricating properties of water started in the 1990s. Cognitive and applicatory factors were the reason for selecting water. Water is a medium in which micelles and LLCs form quite readily. As far as practical applications are concerned, it may function as a base which is safe in terms 
of ecology and fire safety. The results of physicochemical and tribological studies on binary solutions treated as model lubricating substances have been presented in a number of publications [1-15].

This article is a continuation of research on tribological properties of aqueous solutions of alkyl sulfates. Antiseizure properties of these solutions were published earlier in [7]. According to the methodology used, those properties were characterized by scuffing load $\left(P_{\mathrm{t}}\right)$, seizure load $\left(P_{\mathrm{oz}}\right)$ limiting pressure of seizure $\left(p_{\text {oz }}\right)$ [59]. No seizure was observed for a number of solutions and they reached the value of $P_{\mathrm{oz}}$ corresponding to the maximum load for the tribotester used (T-02 tester). The $P_{t}$ and $p_{\text {oz }}$ values were also so high that the solutions fulfilled lubricity criteria for operational fluids. It was interesting to note the non-monotonic changes in the quantities characterizing antiseizure properties as a function of concentration of additives. Therefore, it was decided to carry out tribological tests using the same device (T-02 tester) but under different conditions, i.e., under a steady load $(P=2 \mathrm{kN})$. The quantities measured were the coefficient of friction $(\mu)$ and a wear scar diameter $(d)$ which have an influence on a reduction of energy losses (resistance to motion) and durability of tribological systems (wear).

Typical changes in the coefficient of friction as a function of time for water and water solutions of alkyl sulfates have been shown in Fig. 4. The coefficient of friction for water as a base increases but the change rate decreases with increasing friction time. However, in the case of alkyl sulfate solutions the $\mu$ values decrease rapidly during the first $100 \mathrm{~s}$ of motion and then they stabilize, with a tendency to a small increase, until the measurement is over. The average $\mu$ values from the whole test and from three independent measurements have been shown in Fig. 5. The friction coefficient value for water was 0.40 and was six times higher in comparison with $1 \%$ solutions, while the wear scar diameter was two times smaller than the one in the presence of water.

The dependence of the coefficient of friction (Fig. 5a), wear scar diameter (Fig. 5b), and temperature of the lubricant film after the test (Fig. 5c) as a function of

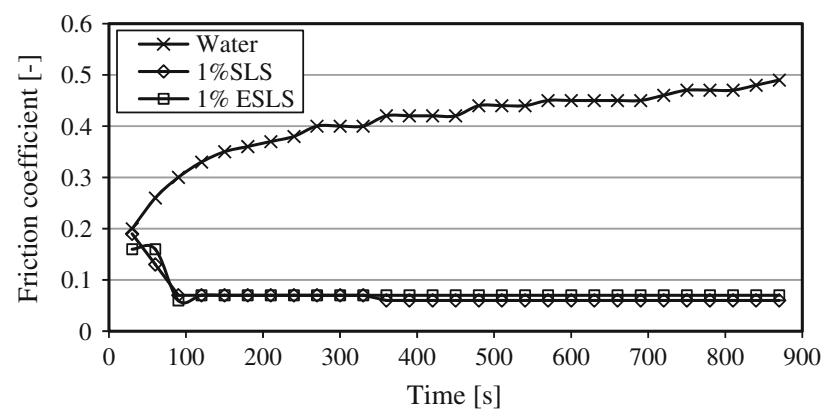

Fig. 4 Examples of dependences of friction coefficient on time
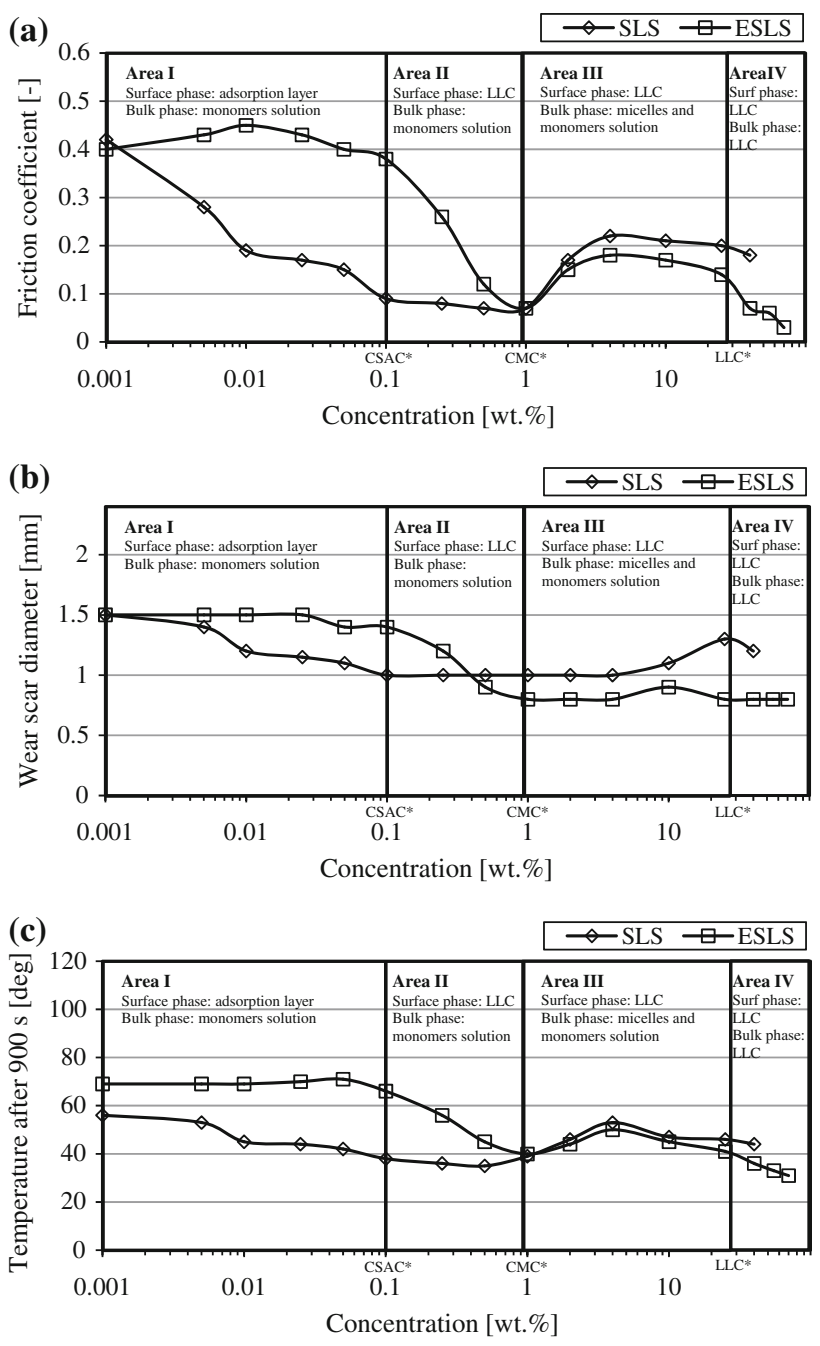

Fig. 5 Dependence of friction coefficient (a), wear scar diameter of balls (b), and temperature after a $900 \mathrm{~s}$ test (c) on concentration of aqueous solutions of SLS and ESLS

concentration were analyzed. The whole range of concentration change was divided into four areas which can be associated with changes in the solutions and at the interface [60]. The points denoted as CSAC*, CMC*, and LLC* may be combined with concentrations corresponding to the presence of micelles in the surface phase and in the bulk phase and to the presence of mesophases in the bulk phase. However, they do not have to be boundary values for the formation of individual structures.

Monomers adsorb on the solid surface for concentrations in the range of Area I in Fig. 5. After exceeding the CSAC value, surface micelles form and their formation ends at a concentration equal to the CMC. At this concentration, an equilibrium between the surface phase and the bulk phase is reached (Area II). Micelles form above the CMC value and their number, sizes and shapes change with an increase in concentration (Area III). The coefficient 
of viscosity $(\eta)$ of solutions in the concentration range in Areas I-III depends on the concentration of additives to a small extent. The $\eta$ values in the $0.001-0.5 \%$ range are comparable to those obtained for water $(\sim 1 \mathrm{mPa} \mathrm{s})$. However, they increase from $1 \mathrm{mPa}$ s to about $1.2 \mathrm{mPa} s$ in the $0.5-4 \%$ range. The increase is significant (up to about $100 \mathrm{mPa} \mathrm{s}$ ) above the concentration of $10 \%$ and those changes may be interpreted as a result of a change of the shape of micelles from spherical into cylindrical. Mesophases form in the bulk phase (Area IV) at the concentrations of about $40 \%$ or more. The values of viscosity coefficients for LLCs are high and characteristic of individual mesophases [7]. The formation of LLCs in the surface phase is expected for Areas II-IV. This is quite obvious in the case of Area IV, whereas in the case of Areas II and III this may result from high surface activity of surfactants. It follows from the law of mass action that the concentration of surfactants in the surface phase may be many times higher than in the bulk phase at high adsorption equilibrium constants. Hence, at the concentration of several percent in the bulk phase, there may appear conditions for the formation of LLCs in the surface phase.

Characteristic changes in the quantities measured as a function of concentration can be observed in individual Areas. Motion resistance, wear and temperature have relatively high values in Area I in which the surface phase is not fully set. SLS solutions exhibit more advantageous properties in this concentration range. Especially large differences can be observed in the changes in the coefficient of friction for which the $\mu$ values are more than four times lower than for ESLS solutions. A difference in temperature of the solutions of the two compounds is also significant and it reaches as much as about $30{ }^{\circ} \mathrm{C}$. Differences in the wear scar diameter values are smaller and the maximum difference is about $0.4 \mathrm{~mm}$ (about 40\%). These results are not in conformity with high activity of ESLS defined by the values of surface tension (Fig. 2). As mentioned before, the reasons for these correlations can be found in the unfavorable configuration of ESLS monomers on the surface. Due to higher hydrophilicity of this compound, the anion may be "deviated" from the surface which may unfavorably affect friction conditions. The concentration range in which surface micelles form (Area II) exhibits a decrease in the quantities measured as a function of time. The quantities reach comparable values at the concentration of the order of one percent (CMC*). SLS solutions have more favorable values up to that concentration value. There occurs an inversion regarding the type of compound in the concentration range in which an equilibrium between monomers and micelles in the bulk phase is expected (Area III). SLS solutions show higher values of motion resistances, wear and temperature than ESLS solutions. The finished process of micelle formation in the surface phase may have a decisive influence on the changes observed. The effect of the micellar structures formed in the surface phase determines tribological properties in Areas II and III. It should be added that liquid crystalline structures may form in the surface phase in Area II and particularly in Area III and they may also lead to positive changes in tribological properties. Mesophases whose type depends on temperature and concentration form both in the surface phase and in the bulk phase in Area IV. So, there may occur a change in liquid crystalline structures under friction conditions. Under static conditions ESLS solutions form two phases: hexagonal (about 40\%) and lamellar (about 70\%) whereas SLS solutions form a lamellar phase (about 40\%). No effect of the viscosity of the identified mesophases on motion resistances has been observed. No increase in the $\mu$ value can be observed even at the $\eta$ values of the order of $10^{6} \mathrm{mPa}$ s which may result from anisotropy of mechanical deformations under conditions of relative motion of friction pair elements. ESLS solutions exhibit lower values of motion resistance, wear and temperature than SLS solutions in Area IV.

\section{Summary}

Alkyl sulfates used as additives can positively modify lubricating properties of water. Compared with water, $1 \%$ solutions have lower values of the coefficient of friction (about sixfold), wear scar diameter (d) (about two times) and temperature of the lubricating medium (by $30^{\circ} \mathrm{C}$ ). On the basis of the analysis of the quantities measured as a function of concentration, a four-area model describing (interpreting) changes in the $\mu, d$, and $t$ values based on structures being formed in the solution and at the interface was proposed.

This is an attempt to combine physicochemical properties of solutions with tribological properties of lubricating substances formed on their bases. An important role is played by liquid crystalline structures on surface which form a lubricating film under friction. Their importance may be indirectly confirmed by the fact that high values of friction coefficients characteristic of the mesophases observed do not have any effect on coefficient of friction. Resistance to motion in the presence of a lubricant does not increase even at the values of the order of $10^{6} \mathrm{mPa} s$ which may result from liquid crystalline anisotropy and the presence of "easy slip" planes.

Multicomponent lubricating substances aiming at specific applications will be formulated on the basis of binary alkyl sulfate solutions.

Acknowledgments The authors would like to thank Dr Dariusz Mucha from the Institute of Catalysis and Surface Chemistry PAS for 
the assistance in the X-ray studies. This research was financed by The National Centre for Research and Development in 2008-2009-Grant NR 150023 04. Financial support to Tomasz Wasilewski offered in the form of a scholarship awarded by the Foundation for Polish Science is kindly acknowledged.

Open Access This article is distributed under the terms of the Creative Commons Attribution Noncommercial License which permits any noncommercial use, distribution, and reproduction in any medium, provided the original author(s) and source are credited.

\section{References}

1. Kumar, D., Biswas, S.K.: Microscopic frictional response of sodium oleate self-assembled on steel. Tribol. Lett. 30, 199-204 (2008)

2. Graca, M., Bongaerts, J., Stokes, J., Granick, S.: Friction and adsorption of aqueous polyoxyethylene (Tween) surfactants at hydrophobic surfaces. J. Colloid Interface Sci. 315, 662-670 (2007)

3. Mistra, S.K., Skold, R.O.: Lubrication studies of aqueous mixtures of inversely soluble components. Colloids Surf. A 170, 91-106 (2000)

4. Boschkova, K., Feiler, A., Kronberg, B., Stalgren, J.J.R.: Adsorption and frictional properties of gemini surfactants at solid surfaces. Langmuir 18, 7930-7935 (2002)

5. Boschkova, K., Kronberg, B., Rutland, M., Imae, T.: Study of thin surfactant films under shear using the tribological surface force apparatus. Tribol. Int. 34, 815-822 (2001)

6. Ratoi, M., Spikes, H.A.: Lubricating properties of aqueous surfactant solutions. Tribol. Trans. 42, 479-486 (1999)

7. Sulek, M.W., Wasilewski, T.: Antiseizure properties of aqueous solutions of compounds forming liquid crystalline structures. Tribol. Lett. 18, 197-205 (2005)

8. Sulek, M.W., Wasilewski, T., Zieba, M.: Tribological and physical-chemical properties of aqueous solutions of cationic surfactants. Indus. Lubr. Tribol. 62(5) (2010)

9. Wasilewski, T.: Aqueous solutions of the mixtures of nonionic surfactants as modern ecological lubricants. In: Biresaw, G., Mittal, K.L. (eds.) Surfactants in tribology, pp. 355-388. CRC (Taylor \& Francis), New York (2008)

10. Wasilewski, T., Sulek, M.W.: Paraffin oil solutions of the mixture of sorbitan monolaurate-ethoxylated sorbitan monolaurate as lubricants. Wear 261, 230-234 (2006)

11. Sulek, M.W.: Aqueous solutions of oxyethylated fatty alcohols as model lubricating substances. In: Biresaw, G., Mittal, K.L. (eds.) Surfactants in Tribology, pp. 325-353. CRC (Taylor \& Francis), New York (2008)

12. Sulek, M.W., Bocho-Janiszewska, A.: The effect of ethoxylated esters on the lubricating properties of their aqueous solutions. Tribol. Lett. 24, 187-194 (2006)

13. Sulek, M.W., Wasilewski, T.: Tribological properties of aqueous solutions of alkyl polyglucosides. Wear 260, 193-204 (2006)

14. Sulek, M.W., Wasilewski, T.: Influence of critical micelle concentration $(\mathrm{cmc})$ on tribological properties of aqueous solutions of alkyl polyglucosides. Tribol. Trans. 52, 12-20 (2009)

15. Sulek, M.W., Wasilewski, T.: Influence of alkylpolyglycosides chain length on tribological properties its aqueous solutions. Tribologie und Schmierungstechnik. 51, 9-13 (2004) (in German)

16. ASTM Standard-ASTM D 5183-05: Standard Test Method for Determination of the Coefficient of Friction of Lubricants Using the Four-Ball Wear Test Machine. ASTM International, West Conshohocken (2008)
17. Fan, A., Somasundaran, P., Turro, N.J.: Adsorption of alkyltrimethylammonium bromides on negatively charged alumina. Langmuir 13, 506 (1997)

18. Wang, J., Han, B., Dai, M., Yan, H., Li, Z., Thomas, R.K.: Effects of chain length and structure of cationic surfactants on the adsorption onto Na-Kaolinite. J. Colloid Interface Sci. 213, 596-601 (1996)

19. Chander, S., Fuerstenau, D.W., Stiger, D.: On hemimicelle formation at oxide/water interfaces. In: Parfitt, G.D., Rochester, C.H. (eds.) Adsorption from Solution at the Solid/Liquid Interface, pp. 197-210. Academic Press, New York (1983)

20. Wu, S.H., Pendleton, P.: Adsorption of anionic surfactant by activated carbon: effect of surface chemistry, ionic strength, and hydrophobicity. J. Colloid Interface Sci. 243, 306-315 (2001)

21. Atkin, R., Craig, V.S.J., Wanless, E.J., Biggs, S.: The influence of surfactant chain length and electrolyte on the adsorption of cationic surfactants at the silica-aqueous interface. J. Colloid Interface Sci. 266, 236 (2003)

22. Levitz, P.E.: Adsorption of non ionic surfactants at the solid/ water interface. Colloids Surf. A 205, 31-38 (2002)

23. Patrick, H.N., Warr, G.G., Manne, S., Aksay, I.A.: Surface micellization patterns of quaternary ammonium surfactants on mica. Langmuir 15, 1685-1692 (1999)

24. Rosen, M.J.: Surfactants and Interfacial Phenomena. Wiley-Interscience Publication, New York (1989)

25. Ptrick, H.N., Warr, G.G.: Self-assembly structures of nonionic surfactants at graphite/solution interfaces. 2. Effect of polydispersity and alkyl chain branching. Colloids Surf. A 162, 149-157 (2000)

26. Ptrick, H.N., Warr, G.G., Manne, S., Aksay, I.A.: Self-assembly structures of nonionic surfactants at graphite/solution interface. Langmuir 13, 4349-4356 (1997)

27. Sivakumar, A., Somasundaran, P.: Adsorption of alkylxylenesulfonates on alumina: a fluorescence probe study. Langmuir 10, 131-134 (1994)

28. Somasundaran, P., Krishnakumar, S.: Adsorption of surfactants and polymers at the solid-liquid interface. Colloids Surf. A 123-124, 491-513 (1997)

29. Somasundaran, P., Huang, L.: Adsorption/aggregation of surfactants and their mixtures at solid/liquid interfaces Adv. Colloid Interface Sci. 88, 179-208 (2000)

30. Hough, D.B., Rendall, H.M.: Adsorption of ionic surfactants. In: Parfitt, G.D., Rochester, C.H. (eds.) Adsorption from Solution at the Solid/Liquid Interface, pp. 247-320. Academic Press, New York (1983)

31. Cases, J.M., Villieras, F., Michot, L.J., Bersilon, J.L.: Long chain ionic surfactants: the understanding of adsorption mechanism from the resolution of adsorption isotherms. Colloids Surf. A 205, 85-99 (2002)

32. Kiraly, Z., Findenegg, G.H.: Calorimetric study of the adsorption of short-chain nonionic surfactants on silica glass and graphite: dimethyldecylamine oxide and octyl monoglucoside. Langmuir 16, 8842-8849 (2000)

33. Nevskaia, D.M., Gurrrero-Ruiz, A., Lòpez-Gonzales, J.: Adsorption of polyoxyethylenic surfactants on quartz kaolin, and dolomite: a correlation between surfactant structure and solid surface nature. J. Colloid Interface Sci. 181, 571-580 (1996)

34. Kronberg, B.: Surfactant mixtures. Curr. Opin. Colloid Interface Sci 2, 456-463 (1997)

35. Howse, J., Steitz, R., Pannek, M., Simon, P., Schubert, D.W., Findenegg, G.H.: Adsorbed surfactant layers at polymer/liquid interfaces, a neutron reflectivity study. Phys. Chem. Chem. Phys. 3, 4044-4051 (2001)

36. Penfold, J., Staples, E.J., Cummins, P., Tucker, I., Thomas, R.K., Simister, E.A.: The structure of the mixed cationic/non-ionic surfactant monolayer of hexadecyltrimethyl ammonium bromide 
and monododecyl hexaethylene glycol at the air-water interface. J. Chem. Soc. 92, 1549 (1996)

37. Atkin, R., Craing, V.S.J., Wanless, E.J., Briggs, S.: Mechanism of cationic surfactant adsorption the solid-aqueous interface. Adv. Colloid Interface Sci. 103, 219-304 (2003)

38. Söderlind, E., Stilbs, P.: Chain conformation of ionic surfactants adsorbed on solid surfaces from carbon-13 NMR chemical shifts. Langmuir 9, 1678-1683 (1993)

39. Patrick, H.N., Warr, G.G.: Self-assembly structures of nonionic surfactants at graphite/solution interfaces. 2. Effect of polydispersity and alkyl chain branching. Colloids Surf. 162, 149-157 (2000)

40. Adler, J.J., Singh, P.K., Patist, A., Rabinovich, Y.I., Shah, D.O., Moudgil, B.M.: Correlation of particulate dispersion stability with the strength of self-assembled surfactants films. Langmuir 16, 7255-7262 (2000)

41. Denoyel, R.: Microcalorimetry and ellipsometry in surfactant adsorption studies. Colloids Surf. A 205, 61-71 (2002)

42. Tiberg, F.: Physical characterization of non-ionic surfactant layers adsorbed at hydrophilic and hydrophobic solid surfaces by time-resolved ellipsometry. J. Chem. Soc. 92, 531 (1996)

43. Gellan, A., Rochester, C.H.: Adsorption of $n$-alkylpolyethylene glycol non-ionic surfactants from aqueous solution onto silica. J. Chem. Soc. Faraday Trans. 81, 2235-2245 (1985)

44. Laughlin, R.G.: The aqueous phase behavior of surfactants. Academic Press, London (1994)

45. Pandey, S., Bagwe, R.P., Shah, D.O.: Effect of counterions on surface and foaming properties of dodecyl sulfate. J. Colloid Interface Sci. 267, 160-166 (2003)

46. Esposito, C., Colicchio, P., Facchiano, A., Ragone, R.: Effect of a weak electrolyte on the critical micellar concentration of sodium dodecyl sulfate. J. Colloid Interface Sci. 200, 310-312 (1998)

47. Yang, J.: Viscoelastic wormlike micelles and their applications. Curr. Opin. Colloid Interface Sci. 7, 276-281 (2002)

48. Shah, S.S., Saeed, A., Sharif, Q.M.: A study of micellization parameters and electrostatic interactions in micellar solution of sodium dodecyl sulfate. Colloids Surf. A 155, 405-412 (1999)

49. Shah, S.S., Jamroz, N.U., Sharif, Q.M.: Micellization parameters and electrostatic interactions in micellar solution of sodium dodecyl sulfate (SDS) at different temperatures. Colloids Surf. A 178, 199-206 (2001)

50. Mokrushina, L., Churyusova, T., Savchuk, K., Morozowa, Y., Smirnova, N.: Critical micelle concentration and phase behavior of aqueous mixtures of dodecylsulfates and sodium ethoxydodecylsulfate. Fluid Phase Equilib. 194-197, 1077-1087 (2002)

51. Jaschke, M., Butt, H.J., Gaub, H.E., Manne, S.: Surfactant aggregates at a metal surface. Langmuir 13, 1381-1384 (1997)

52. Manne, S., Schäffer, T.E., Huo Q., Hansma, P.K., Morse, D.E., Stucky, G.D., Aksay, I.A.: Gemini surfactants at solid-liquid interfaces: control of interfacial aggregate geometry. Langmuir 13, 6382-6387 (1997)

53. Dixit, S.G., Vanjara, A.K., Nagarkar, J., Nikoorazm, M., Desai, T.: Co-adsorption of quaternary ammonium compounds-nonionic surfactants on solid-liquid interface. Colloids Surf. A 205, 39-46 (2002)

54. Wanless, E.J., Davey, T.W., Ducker, W.A.: Surface aggregate phase transitions. Langmuir 13, 4223-4228 (1997)

55. Wall, J.F., Zukoski, Ch.F.: Alcohol-induced structural transformations of surfactant aggregates. Langmuir 15, 7432-7437 (1999)

56. Brick, J., Jönsson, B., Tiberg, F.: Kinetics of nonionic surfactant adsorption and desorption at the silica-water interface: one component. Langmuir 14, 1058-1071 (1998)

57. Corkill, J.M., Goodman, J.F., Tate, J.R.: Adsorption of non-ionic surface-active agents at the graphon/solution interface. Trans. Faraday Soc. 62, 979-986 (1966)

58. Clunie, S.J., Ingram, B.T.: Adsorption of nonionic surfactants. In: Parfitt, G.D., Rochester, C.H. (eds.) Adsorption from Solution at the Solid/Liquid Interface, pp. 105-152. Academic Press, New York (1983)

59. Piekoszewski, W., Szczerek, M., Tuszynski, W.: The action of lubricants under extreme pressure conditions in a modified fourball tester. Wear 240, 183-193 (2001)

60. Paria, S., Manohar, C., Khilar, K.C.: Effect of cationic surfactant on the adsorption characteristics of anionic surfactant on cellulose surface. Colloids Surf A 232, 139-142 (2004) 